\title{
O esporte na política colonial portuguesa: as iniciativas de Sarmento Rodrigues na Guiné (1945-1949)
}

The sport in the Portuguese colonial policy: the actions of Rodrigues Sarmento in Portuguese Guinea (1945-1949)

Victor Andrade de Melo*

\section{Resumo}

$\mathrm{O}$ artigo tem por objetivo discutir as iniciativas ligadas ao esporte entabuladas no âmbito da administração do governador da Guiné Portuguesa Manuel Maria Sarmento Rodrigues, cargo ocupado entre março de 1945 e janeiro de 1949. Como fontes foram utilizados os seus discursos governamentais; o Boletim Cultural da Guiné Portuguesa, periódico dedicado à divulgação de pesquisas e principais ocorrências da colônia; e $O$ Arauto, único jornal da província na ocasião. Conclui-se que Sarmento Rodrigues inaugurou o apoio sistemático ao esporte na política colonial portuguesa, inserido em suas preocupações com o desenvolvimento e o respeito às peculiaridades locais, posturas que iriam se manifestar quando ocupasse outros postos no regime, ligadas a mudanças na concepção de intervenção no ultramar.

Palavras-chave: História do esporte; História da África; colonialismo.

\section{Abstract}

The article aims to discuss the Manuel Maria Sarmento Rodrigues initiatives related to sport when he served as governor of Portuguese Guinea, between March 1945 and January 1949. As sources were used the speeches of Sarmento Rodrigues; the Boletim Cultural da Guiné Portuguesa, dedicated to the dissemination of research and facts of the colony; and $O$ Arauto, the only newspaper of the province at that time. We concluded that Sarmento Rodrigues inaugurated the sports support as government policy, inserted in his concerns about development and respect of local peculiarities, positions that would clearly manifest when he occupying other positions in the Portuguese government, linked to changes in the design of colonial intervention.

Keywords: Sport history; History of Africa; colonialism.

\footnotetext{
* Programa de Pós-Graduação em História Comparada/Instituto de História, e Programa de PósGraduação em Educação, Faculdade de Educação, Universidade Federal do Rio de Janeiro (UFRJ). victor.a.melo@uol.com.br
} 
Desde os anos 1970, têm sido realizados estudos sobre a presença do esporte nas colônias africanas da Inglaterra e da França, tanto no que se refere a sua manifestação cotidiana quanto no que tange à sua mobilização mais explicitamente política, seja por agências metropolitanas, seja por lideranças anticoloniais. Já no tocante aos territórios de Portugal na África, só bem recentemente essas investigações vêm sendo entabuladas (Melo, 2011a).

Essa lacuna tem sido preenchida por estudos como os reunidos por Melo, Bittencourt e Nascimento (2010) e Nascimento, Bittencourt, Domingos e Melo (2013), que demonstram a vitalidade e a importância que ocupou o fenômeno esportivo tanto nas antigas colônias quanto nos já independentes países africanos de língua oficial portuguesa.

No contexto desses esforços, uma possibilidade de investigação é prospectar a presença do esporte no âmbito da política colonial portuguesa. Segundo Melo (2011b), é a partir da segunda metade dos anos 1940 que "a prática foi paulatinamente encarada como uma ferramenta adequada para auxiliar a consolidar a unidade do Império e expressar as supostas contribuições do colonizador para civilizar o indígena" (p.216).

Trata-se de uma apreensão genérica, que, a despeito de sua pertinência, carece de maior profundidade e precisão. Como teriam as lideranças metropolitanas perspectivado e encaminhado ações tendo o esporte como foco? A que interesses e expectativas atendia tal intervenção? Tendo em conta essas questões, este artigo tem por objetivo discutir as iniciativas ligadas ao esporte entabuladas no âmbito da administração do governador da Guiné Portuguesa Manuel Maria Sarmento Rodrigues, cargo ocupado entre março de 1945 e janeiro de 1949.

Como, por motivos diversos, a Guiné foi "o primeiro campo de ensaio dos rumos autonomistas e desenvolvimentistas da política portuguesa" (Silva, 2008, p.32), isto é, uma primeira experiência de mudança de rumos na intervenção metropolitana na África, processo no qual Sarmento Rodrigues desempenhou papel protagonista, argumentamos que esse estudo pode contribuir para melhor entender a ação de Portugal nos seus territórios do ultramar. Dessa forma, permite-nos lançar um olhar tanto para o colonialismo como um todo quanto para a presença do esporte em cenários coloniais.

Vale destacar que até a década de 1940, mesmo na metrópole, ainda não era usual tanto uma maior atenção governamental com o esporte quanto a sua mobilização no âmbito dos interesses da nação. Foi mesmo a partir daquele momento que a prática passou a ser mais valorizada politicamente, tendo em 
conta a construção de um sentido de nacionalidade que se articulava com os intuitos do governo Salazar (Neves, 2009; Drumond, 2014).

Para alcance do objetivo, utilizamos como fontes os discursos de Sarmento Rodrigues na condição de governador da Guiné, reunidos em livro publicado em Lisboa, em 1949; o Boletim Cultural da Guiné Portuguesa, criado em conjunto com o Centro de Estudos da Guiné Portuguesa, com o objetivo de divulgar as pesquisas e principais ocorrências da colônia; e O Arauto, o único jornal da colônia na ocasião, lançado em 1943, pela Igreja católica de Bolama, depois transferido para Bissau. ${ }^{1}$

Trata-se de uma "visão oficial" sobre a atuação de Sarmento Rodrigues, já que prospectada a partir de seus próprios discursos e das representações sobre suas realizações publicadas no Boletim Cultural, um periódico editado por agência governamental e fiscalizado pela censura. As informações sobre o esporte eram da lavra de Peixoto Correia, chefe de gabinete do governador. Mesmo $O$ Arauto, ainda que independente, naquele momento não entabulava grandes reações à administração colonial.

Sarmento Rodrigues explicitamente registrou seus feitos, enfatizando suas realizações, possivelmente tendo em vista seus projetos futuros, individuais (isto é, aquilo que tange a suas ambições de carreira) e para o Império (suas propostas para a nação e seus olhares para o papel que deveria ocupar o ultramar).

\section{SARMENTO Rodrigues NO LABORATÓRIO DA GUINÉ}

Quando Sarmento Rodrigues assumiu o cargo de governador da Guiné, em 1945, a colônia ainda estava em processo de estruturação administrativa. Até meados da década de 1930, persistiram conflitos com povos locais, especificamente no arquipélago de Bijagós, mesmo que a essa altura já se tivessem estabelecido importantes alianças (notadamente com os fulas) e/ou controle da maior parte das etnias. Tratava-se, além disso, de um território que por suas características físicas apresentava muitas dificuldades no que tange à ocupação e ao desenvolvimento econômico (Murteira, 1999).

De fato, somente a partir de meados dos anos 1920 começara a se construir uma melhor infraestrutura urbana na colônia, relacionada também à implantação das primeiras empresas de maior porte, como a Estrela de Farim e, especialmente, a Casa Gouvêa (ligada à Companhia União Fabril/CUF), ambas fortemente envolvidas com a cultura do amendoim. Em 1942, a capital 
foi transferida de Bolama para Bissau, que efetivamente já ocupava um lugar central na vida econômica da Guiné.

Foi só mesmo nos anos 1940 que se tornou mais clara a ação da metrópole e a consolidação de um modelo que vai marcar a colônia até sua independência. Dirigentes e técnicos da metrópole ocupavam o topo das relações hierárquicas. Muitos cabo-verdianos atuavam na administração pública e privada, especialmente no comércio, formando assim um estrato intermediário. Os indígenas compunham um grande grupo inferior (ainda que alguns desses tenham chegado a ocupar cargos no setor intermediário). ${ }^{2}$

Para que se tenha uma noção da composição societária da Guiné, em 1950 havia cerca de 513 mil habitantes, entre os quais somente em torno de 8.300 eram considerados "civilizados", sendo aproximadamente $75 \%$ de mestiços e negros, majoritariamente naturais de Cabo Verde. Entre esses, grande parte possuía pouco tempo de escolarização; apenas 115 pessoas tinham nível superior, sendo vinte negros ou mestiços. Em Bissau viviam cerca de 3.800 pessoas (Cristovão et al., 2005; Silva, 2006).

A atuação de Sarmento Rodrigues na Guiné deve ser compreendida no âmbito das iniciativas em curso na época, por parte da metrópole, para melhor controlar o espaço colonial do ponto de vista material e simbólico (Fernandes, 1999), já incorporando, todavia, algumas mudanças. Ele chegara ao cargo de governador logo depois da nomeação de Marcello Caetano para o Ministério das Colônias, cuja administração foi marcada tanto pela reafirmação dos princípios básicos da ação portuguesa nos territórios do ultramar quanto por intenções de renovar a política colonial, na esteira dos desdobramentos desencadeados no período pós-Segunda Guerra Mundial. ${ }^{3}$

Sarmento Rodrigues se alinhava a essa nova perspectiva de ação colonial. Quando chegou à Guiné, já tinha uma longa trajetória como militar ${ }^{4}$ e conhecia a realidade colonial. Atuara na Índia portuguesa e em Moçambique e cursara dois anos na Escola Superior Colonial (Ferrão, 1999). Do ponto de vista político, adotava posições conservadoras, todavia mais liberais do que a maioria dos envolvidos com o regime português (Leonard, 1997). Em muitas ocasiões, de fato, tomou posições de independência em relação ao governo. ${ }^{5}$

Desde o início, Sarmento Rodrigues demonstrou a intenção de promover o progresso material e espiritual da colônia. No decorrer de sua gestão, efetivamente promoveu muitas intervenções infraestruturais, mas também diversas iniciativas no âmbito da educação e da cultura, inclusive no que tange à melhor compreensão das peculiaridades locais, cujos melhores indicadores são a criação dos já citados Centro de Estudos da Guiné Portuguesa e Boletim Cultural 
da Guiné Portuguesa, assim celebrados por ele: “É tempo da Guiné ser mais alguma coisa do que um campo fértil de produtos materiais. É preciso que pelo valor de seus habitantes se transforme num meio onde floresçam também as culturas do espírito, acima de todas expoentes de uma civilização" (Rodrigues, 1949, p.89).

Vale registrar que Sarmento Rodrigues, no decorrer de sua vida, sempre teve grande ligação com as questões culturais, até mesmo estabelecendo muitos contatos com artistas e intelectuais; foi membro de várias entidades científicas. Em sua trajetória, sempre dedicou atenção a esse aspecto, foi um dinamizador da política cultural colonial (Ferrão, 1999).

Aliás, Sarmento Rodrigues também teve forte relação pessoal com o esporte. Foi praticante de algumas modalidades, especialmente do tênis, e membro de muitos clubes desde a juventude, tendo sido por muitas agremiações (da Ásia, África e Europa) homenageado com títulos honoríficos por suas contribuições.

Outra importante marca de sua gestão na Guiné foi a busca de distensionar as relações com os indígenas, propugnando a necessidade de melhor entender e respeitar as culturas locais, ${ }^{6}$ a despeito de em momento algum ter abandonado suas posturas coloniais, a todo tempo reiterando a missão civilizadora de Portugal. Silva (2006) lembra que durante anos entre os nativos ecoou o respeito pelo nome de Sarmento Rodrigues.

Da mesma forma, procurou estabelecer maior igualdade de oportunidades entre metropolitanos, colonos e indígenas. Entre as inovações que introduziu por ocasião de seu governo na Guiné, algumas que depois foram incorporadas na política colonial portuguesa, extinguiu a categoria de assimilados, mantendo somente a divisão entre civilizados/cidadãos e indígenas. ${ }^{\text {? }}$

Um diferencial de sua atuação foi procurar ter em conta as peculiaridades do cotidiano e as experiências dos que viviam no ultramar. Ao chegar a Bissau e assumir as funções de governador, em sessão do Conselho de Estado, Sarmento Rodrigues surpreendeu ao declarar não ter plano de governo pronto, pretendendo elaborá-lo em conjunto com as lideranças locais, dos mais diversos setores. Dizendo-se sensível às dificuldades da colônia, demonstrou preocupação em "fazer o possível por conseguir mais conforto e bem-estar para todos" (Rodrigues, 1949, p.15), ${ }^{8}$ garantindo "habitações higiênicas; higiene nas ruas e em volta das povoações, meios de vida mais fáceis; ambiente social cada vez mais digno; satisfação de necessidades espirituais”.

Sarmento Rodrigues fortaleceu os órgãos consultivos colegiados, como a Conferência de Administradores e o Conselho de Estado. Na verdade, logrou 
bastante sucesso como governador da Guiné; suas ações repercutiram durante muitos anos. ${ }^{9}$ Ocupou uma posição protagonista no regime português. Chegou a ser ministro das Colônias/do Ultramar (1950-1955), aprofundando o processo de reformulação da política colonial, momento no qual foi revogado o Ato Colonial, decisão para a qual desempenhou papel de grande importância. Como sugere Ferrão (1999, p.99):

a obra política de Sarmento Rodrigues nas várias funções desempenhadas (governador colonial, ministro e deputado) refletiu os seus ideais maçônicos e filantrópicos, ao mesmo tempo que teve uma projeção prática de grande alcance, $o$ que levou ao reconhecimento público dos seus méritos de Estadista e a uma série de homenagens que lhe foram feitas no final da vida.

Vale ainda lembrar que Sarmento Rodrigues foi um dos responsáveis por promover a aproximação do regime de Salazar com as ideias de Gilberto Freyre, pela adoção do luso-tropicalismo como um dos sustentáculos da política colonial portuguesa. ${ }^{10}$

Vejamos como esse líder político com características tão peculiares tratou o esporte em seu tempo de governador no "laboratório" da Guiné.

\section{As iniciativas esportivas de Sarmento Rodrigues}

Poucos dias após ter chegado à Guiné, em 28 de abril de 1945, Sarmento Rodrigues compareceu a um "Porto de honra" oferecido na Associação Comercial, Industrial e Agrícola. Tratou-se de uma cerimônia de recepção ao novo governador. Entre os promotores se encontravam representantes da União Desportiva Internacional de Bissau (UDIB), mais antiga agremiação da colônia, fundada em 1929, ${ }^{11}$ e do Sporting Club de Bissau, criado em $1936 .{ }^{12}$

No seu discurso de agradecimento (que denominou "Harmonia, condição necessária"), Sarmento Rodrigues dedicou grande atenção à prática esportiva:

Quando penso no desporto lembro-me sempre de união, escola de lealdade, de energia, de perseverança, de correção. Aprende-se lá a perder sem recriminações. As diferenças sociais esbatem-se ou desaparecem. As questões pessoais não existem: o campo da fraternidade está à vista. Qual de nós poderia sofrer uma justa punição por uma falta cometida sem ficar com um bocadinho de azedume para 
quem legitimamente a promoveu? Raros, meus senhores, a não ser os desportistas. (Rodrigues, 1949, p.22)

Seu olhar para a prática estava claramente enquadrado por seu conhecimento dos clássicos da Antiguidade Clássica. Para o governador, ainda que o esporte tenha potencialidades, dever-se-ia tomar cuidado para que elas pudessem se manifestar adequadamente. Em tom de alerta, adverte:

Ora, o futebol, justamente um belo jogo e o favorito, tem as suas falhas. O público apaixona-se, por vezes, mais pelas vitórias do que pelo bom jogo. Sem que devamos deixar de apreciar o ardor combativo, melhor seria admirar sem reservas e aclamar os bons jogadores. (Rodrigues, 1949, p.23)

Nessa ocasião, manifestou seu desejo, naquela altura ainda impreciso, de apoiar a melhor estruturação do esporte na colônia: "Eu tive e tenho o maior empenho em auxiliar o desenvolvimento desportivo" (Rodrigues, 1949, p.23). Deve ter-lhe agradado o discurso, proferido em nome das agremiações esportivas, de João Leal da Silva Tendeiro, futuramente um dos seus mais costumeiros colaboradores na governança da Guiné.

Seu posicionamento se aproximava de algumas crenças de Sarmento Rodrigues, bem como lhe apresentava alguns parâmetros que poderia considerar. Para Tendeiro, no quadro contextual da colônia, o esporte seria um importante elemento de união da população local, uma ferramenta para superar preconceitos diversos que persistiam:

as pequenas e grandes divergências suscetíveis de se erguerem entre europeus e africanos; as possíveis impertinências ditadas pelo complexo de inferioridade que o orgulho da cor representa; a diferença concepcional de reações sociais originada por comportamentos biopsicológicos diferentes - constituem outros tantos elementos desagregadores que se apagam irremediavelmente no campo desportivo. $^{13}$

Tendeiro conclamava pelo apoio do novo governador, informando que as agremiações esportivas encontravam dificuldades para se manter em funcionamento e promover competições. As condições para uma melhor estruturação do esporte eram mesmo precárias: baixo desenvolvimento econômico, fraco mercado interno consumidor, grande heterogeneidade populacional, deficiente nível educacional, condições físicas e climáticas (como uma intensa estação de chuvas) que criavam dificuldades. 
Em O Arauto, pode-se perceber efetivamente que os clubes vinham tentando organizar partidas de futebol, basquete e tênis, sem que as iniciativas lograssem grande continuidade. Mais ainda, grassava uma insatisfação com a qualidade técnica: "Por falta de treinadores especializados, o jogo de futebol na Guiné não tem progredido tecnicamente de modo a evidenciar conjunto e eficiência capazes, embora existam cá bons elementos jovens suscetíveis de melhora". ${ }^{14}$

A criação do Sport Lisboa e Bissau, um clube ligado ao Benfica, que contava com muitos cabo-verdianos entre os associados, trazia esperanças para recrudescer o interesse pelo esporte, até mesmo em função de melhoria do padrão técnico dos jogos, aspecto no qual os oriundos de Cabo Verde já demonstravam maior avanço. ${ }^{15}$ Assim celebra o novo momento $O$ Arauto, já com uma coluna dedicada ao tema (Vida Desportiva):

Há três anos o desporto na Guiné vinha decaindo escandalosamente, enquanto que a mocidade se preocupava demasiado com os bailes. Felizmente as coisas parecem que vão mudando de rumo. Este ano a vida desportiva começou com entusiasmo como se vê pelos desafios que passamos a relatar. ${ }^{16}$

Quando Sarmento chegou à colônia, portanto, havia movimentos de recuperação do interesse pelo esporte, notadamente pelo futebol. As ações do governador, todavia, de maneira alguma foram meramente ocasionais. Em diversas ocasiões, demonstrou entender que o apoio à prática se inseria nos seus projetos de promoção do desenvolvimento local; seria um dos elementos que poderia contribuir para o progresso da Guiné.

Esse olhar se percebe claramente quando apresentou as linhas de ação que pretendia adotar na sua gestão, numa sessão do Conselho do Governo, realizada em 3 de junho de 1945. Entre as diversas iniciativas que prometeu entabular, não deixou de citar o esporte, convocando os clubes a auxiliá-lo na tarefa: "Quanto aos desportos, espero que em dia me apareçam os seus representantes para apresentarem as suas aspirações, que muito gostava de apreciar e ajudar" (Rodrigues, 1949, p.50).

De fato, estabeleceu-se um contato entre o governo e as agremiações. Um programa de metas foi traçado. Em junho de 1947, Sarmento Rodrigues celebra, na $1^{\text {a }}$ Conferência dos Administradores, os bons resultados dessa articulação, os avanços observáveis no âmbito esportivo. Na ocasião, uma vez mais ressaltou que considerava a prática como um assunto importante "no progresso de uma terra, pois que através dela se procura a fortaleza do corpo, e não 
menos a do espírito" (Rodrigues, 1949, p.284). Fez questão de registrar que era o governador que até então mais investira no esporte, enumerando suas realizações.

Para o sucesso de suas iniciativas, no seu modo de entender, teria sido fundamental o envolvimento coletivo, potencializado graças a uma de suas ações:

Tudo isso foi possível depois de se ter conseguido um completo entendimento das organizações desportivas, através do Conselho de Desportos. O governo arcou gostosamente com despesas muito superiores a qualquer previsão, e que ninguém lembraria de pedir-lhe; bastou para tanto ter a garantia do sucesso. (Rodrigues, 1949, p.285)

O Conselho de Desportos foi criado por Sarmento Rodrigues logo nos seus primeiros meses na Guiné, em agosto de 1945. Era formado por um delegado do governo, na condição de presidente (o primeiro a ocupar o cargo foi o $1^{\circ}$ tenente Antônio Augusto Peixoto Correia, seu chefe de gabinete, que já vinha atuando na direção da UDIB), um representante da Comissão Municipal de Bissau (a princípio Antônio Joaquim de Campos) e um representante de cada clube da capital (João Leal da Silva Tendeiro, pela UDIB; Severino Gomes de Pina, pelo Sporting; e Augusto das Neves Pimenta, pelo Sport Lisboa e Bissau). Segundo previa a portaria de criação, cabia ao órgão “orientar e disciplinar o desporto - justamente considerado como elemento indispensável ao revigoramento do indivíduo e também um meio valioso de educação popular -; auxiliar os clubes na importante missão que lhes cabe". ${ }^{17}$

Vale destacar que os representantes das agremiações eram personagens destacados da colônia. Tendeiro foi membro do Centro de Estudos da Guiné e um dos mais profícuos estudiosos da flora e da cultura local. Pina ocupou cargos importantes na administração, inclusive no Conselho de Governo. Pimenta também desempenhou relevantes funções na burocracia colonial.

Parece que, a princípio, houve certa desconfiança por parte dos clubes com a proposta do Conselho. Segundo Sarmento Rodrigues, as agremiações pensavam que o governo desejava "manobrá-las como entendesse para seu proveito, tirando-lhes a liberdade” (1949, p.478). Todavia, logo as lideranças esportivas teriam percebido que as intenções eram as melhores, e que havia real vontade de execução das propostas. Para o governador, ao fim e ao cabo, o mais importante a celebrar é que "o progresso do desporto e os triunfos dos jogadores transformaram-se em benefícios e em prestígio para a Guiné” (1949, p.478). 
Mesmo que a relação não tenha sido tão harmônica como pretendeu passar Sarmento Rodrigues, inegavelmente lograra bons resultados a atuação do Conselho. Em 1948, estavam ativos nove clubes, três dos quais fundados desde a criação da entidade, estando prevista para breve a inauguração de mais dois; eram promovidos com regularidade torneios de preparação, campeonatos regionais e campeonatos da Guiné, todos de futebol, além de diversas contendas de outras modalidades; eram realizados desafios internacionais com as colônias vizinhas -Gâmbia, de posse da Inglaterra, e Senegal, dirigido pelos franceses.

Essa foi uma das ações mais estimuladas por Sarmento Rodrigues. Não se tratava exatamente de uma novidade a promoção de jogos com clubes dos territórios fronteiriços. Por exemplo, em abril de 1945, já contando com a destacada presença do governador como espectador, o Sporting Club disputou uma partida com a seleção de Ziguinchor, uma cidade do Senegal que possuía fortes laços com a Guiné (fizera parte do território até 1886, quando foi cedida à França).

Nessa ocasião, que contara com grande público (o campo teve o "maior número de assistência jamais visto"), ${ }^{18}$ e a vitória da equipe local foi assim saudada pelo Arauto: "Nossos desportistas saíram vitoriosos mostrando mais uma vez ... que o desporto em Portugal não desmerece atenção e carinho". Certamente o governador gostou do que viu, uma inspiração para ações que tomaria no futuro.

Se antes esses desafios eram iniciativas dos clubes, no tempo de Sarmento Rodrigues passaram a ser também uma ação do Estado, mais fortemente relacionada à ideia de nacionalidade. Nessas ocasiões, "civilizados e indígenas" podiam louvar as cores do pavilhão português. Isso não se restringia aos jogadores, estendendo-se às arquibancadas normalmente lotadas. Vale destacar que as equipes da Guiné não possuíam somente brancos europeus, mas também mestiços cabo-verdianos e mesmo "civilizados" guineenses. Na Figura 1 podemos ver as bandeiras nacionais hasteadas, situação comum nesses desafios internacionais.

Esses encontros eram também marcados por intenções diplomáticas. Se no passado houvera conflitos diversos ligados às fronteiras, essas oportunidades ajudavam a reforçar laços de cooperação e celebrar interesses de integração para resolução de problemas em comum. Tratava-se de tentar colocar Portugal no seio das ações que se estabeleciam naquela região da África.

Uma primeira iniciativa se deu em 1947, quando Sarmento Rodrigues esteve em Dacar para saudar a visita do presidente da França ao Senegal. No caminho, passou por Bathurst (atual Banjul, capital da Gâmbia), a fim de 


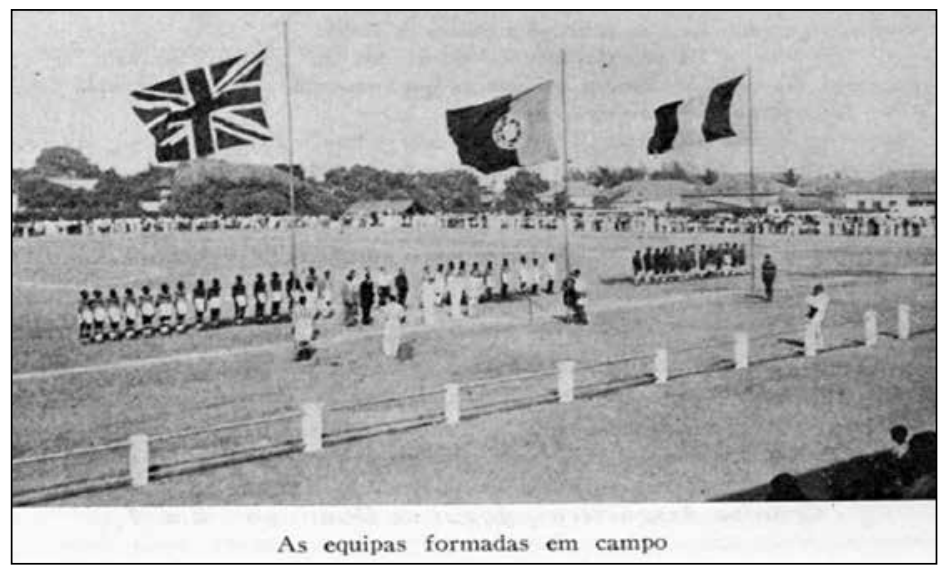

Figura 1 - Boletim Cultural da Guiné Portuguesa, Bissau, v.4, n.15, 1949.

estabelecer contatos. Nesse mesmo ano aconteceu, em Bissau, um desafio internacional: jogos de futebol e tênis entre equipes da UDIB e do Clube Náutico de Dacar, uma promoção do Conselho de Desportos. Em retribuição, partidas semelhantes foram realizadas na capital da colônia francesa. Assim saudou-se o evento no Boletim:

Todas as provas decorreram no meio de grande camaradagem e espírito desportivo, sendo estes dois contatos aproveitados para se firmar o estabelecimento de cordiais relações entre os desportistas franceses e os nossos, ponto de partida para o prosseguimento do intercâmbio agora iniciado, segundo um plano mais amplo de competições internacionais. ${ }^{19}$

A Figura 1 refere-se a um dos eventos mais celebrados no período de Sarmento Rodrigues, o Torneio Internacional de Futebol da África Ocidental, disputado em 1948 em Dacar, e em 1949 em Bissau, neste caso uma promoção do Conselho de Desportos. Participaram equipes de Bathurst, Dacar e São Luís (cidade do Senegal), além da seleção local, que se sagrou vencedora nas duas contendas. As conquistas foram narradas como épicos, consideradas como sinal dos avanços da Guiné e da fibra do homem português.

A vitória na edição do Torneio de 1948 foi encarada como a primeira grande conquista internacional esportiva da colônia. Quando a equipe retornou a Bissau, organizou-se um grande cortejo; no dia, o comércio fechou as portas 
e os funcionários públicos foram liberados mais cedo. Sarmento Rodrigues recebeu, no aeroporto, os jogadores e dirigentes, acompanhando a pé o desfile. Foi saudado como um dos responsáveis pelo sucesso da seleção local. ${ }^{20}$

Uma grande recepção foi oferecida na UDIB, marcada por muita alegria, celebração e discursos das autoridades presentes. Peixoto Correia, ao agradecer aos que teriam contribuído para a campanha, fez questão de saudar o governador pelo desenvolvimento do esporte na Guiné, enumerando suas ações.

No discurso que encerrou a cerimônia, Sarmento Rodrigues também relacionou a conquista a suas propostas e ações na Guiné. Para ele, a vitória em Dacar consagrara a linha de atuação do governo, do Conselho de Desportos e dos clubes. Os jogadores, por sua vez, "ficaram a saber de uma vez para sempre que valem tanto ou mais que os das outras terras maiores em extensão e em população". ${ }^{21}$ Eles teriam sido verdadeiros heróis, "os que marcaram sua superioridade, os que deram nomeada à sua terra, os que melhor honraram, sobretudo pelo seu mérito, o mandato que lhes fora confiado". Tratava-se de uma demonstração de que valeu a pena o investimento no esporte.

Para celebrar ainda mais, o Boletim deu publicidade aos elogios proferidos nos jornais de Dacar, bem como ao ofício que o Conselho de Desportos recebeu do presidente da Liga de Futebol do Senegal, em que reconhecia que a equipe de Bissau tinha dado "um espetáculo nunca visto" naquela colônia, demonstrando o que é "verdadeiramente jogar futebol". ${ }^{22}$ Os resultados foram considerados como frutos de uma "forma científica" de praticar a modalidade.

Relacionava-se esse avanço na qualidade técnica ao principal investimento de Sarmento Rodrigues: a construção de novas instalações. O seu governo financiou a compra ou reforma de sedes de clubes ou campos de jogos localizados em Bolama, Bafatá, Mansoa, Farim, Catió, Canchungo e, principalmente, em Bissau. Essas obras eram acompanhadas pelo Boletim e foram muito celebradas por ocasião das inaugurações, festividades que contaram com a presença de grande público, de "civilizados e indígenas", e de muitas autoridades da província, inclusive o governador.

A mais importante reforma foi a das instalações da UDIB, com a construção de equipamento esportivo muito aguardado pela população, uma promessa que fora lançada já por ocasião da criação do Conselho de Desportos. Com grande festa e enorme público, e com a presença de todos os clubes da província, em junho de 1948 realizou-se a inauguração de um estádio que possuía confortáveis arquibancadas cobertas, vestiários, enfermaria, salas para a direção, bar, campo de futebol, pista de atletismo, quadras de tênis e quadra para hóquei sobre patins, além de espaço reservado para futuras quadras de basquete e voleibol. 
O discurso de Sarmento Rodrigues nessa ocasião proferido, intitulado "Entrego tudo isto, e os meus votos confiados, à mocidade", é uma síntese de seus posicionamentos sobre o esporte. De início, o governador repete os já costumeiros elogios à prática: "a mais salutar e porventura a mais benéfica atividade humana: a cultura física, preparatória dos grandes conquistas reservadas ao espírito" (1949, p.477). Sugere, assim, que o novo equipamento seria uma escola de educação física e moral, local adequado para que se trabalhe "a riqueza de músculos e a fortaleza de ânimo" (p.479).

Como de costume, articula essa compreensão com o papel que teria desempenhado sua administração, o cumprimento de uma promessa feita nos primeiros momentos da sua gestão: "a consagração pública do que valem, do muito que merecem e da grande atenção que desde o primeiro dia o governo tem prestado aos desportistas". A inauguração do estádio seria o auge de uma administração que teria priorizado o esporte, cujos resultados seriam perceptíveis por todos: "clubes engrandecidos, novos organismos formados, vida eficiente, atividade até aqui nunca igualada, êxitos retumbantes dentro e fora das fronteiras, instalações novas e dignas" (p.478).

O discurso de Sarmento Rodrigues se encerra com uma mensagem eloquente, articulando a experiência dos indivíduos com os interesses da nação: "Entrego tudo isto, e os meus votos confiados, à mocidade. Para que ela saiba fazer a sua vida com brio e lealdade, generosa e alegre, saudável de corpo e alma, como eu gostaria que fosse em todas as facetas esta nossa Guiné” (1949, p.479).

A grandiosidade da iniciativa foi enfatizada em todos os discursos. Para Peixoto Correia, tratava-se da mais importante realização de todos os tempos no esporte da Guiné, bem como uma das mais relevantes na colônia em todos os âmbitos, "uma data gloriosa para a mentalidade portuguesa", uma realização do Império, "um fator a concorrer para a civilização da gente desta província, um centro de civismo a juntar-se aos demais pilares da sua vida de espírito". ${ }^{23}$ É uma fala cheia de elogios ao governador, o que é compreensível em função de sua condição de chefe de gabinete.

Não menos elogioso foi o discurso do representante da UDIB, Manuel dos Santos, que afinal viu reformadas as instalações de 1929, um antigo desejo dos associados, sempre adiado por falta de recursos. O antigo colono, fundador do clube, fez questão de celebrar seus antigos companheiros, aqueles que mantiveram viva a agremiação, mesmo com todas as dificuldades enfrentadas.

Ao agradecer a todos que ajudaram o clube em sua caminhada, ressaltou os nomes de Sarmento Rodrigues e Peixoto Correia, lembrando que cumpriram 
todos os acordos com a agremiação estabelecidos, não desapropriando as antigas instalações, sequer fazendo modificações sem consultar a diretoria.

Com o estádio inaugurado nos seus últimos meses na Guiné, Sarmento Rodrigues sacramentou sua atuação no âmbito do esporte. Seria lembrado por muitos anos, tanto mais por ser deficiente, em vários âmbitos, o desempenho do novo governador, Raimundo Antônio Rodrigues Serrão (Silva, 2008). Independentemente disso, pela excelência de suas realizações, Sarmento Rodrigues registrava seu nome para a posteridade.

\section{CONSIDERAÇÕES FINAIS}

Em maio de 1949, já tendo se despedido da Guiné, o antigo governador foi homenageado pelos esportistas da província. Numa bela cerimônia, que contou com as principais autoridades locais, inclusive os cônsules das colônias vizinhas, bem como com dirigentes e atletas dos principais clubes esportivos, com as tribunas completamente lotadas, procedeu-se à renomeação do estádio, que passou a se chamar Sarmento Rodrigues. ${ }^{24}$ Instituiu-se ainda uma taça com seu nome, que seria disputada por muitos anos. ${ }^{25}$

Foi uma cerimônia em que se articulou o elogio ao indivíduo com o louvar da nação. Vale destacar que tudo foi dirigido pelo encarregado do governo, tenente-coronel Pinto Cardoso, na medida em que o novo titular do cargo ainda não tinha desembarcado na Guiné. Definitivamente relacionava-se o nome de Sarmento Rodrigues ao esporte, e tal ligação acabou sendo uma das maiores celebrações dos bons serviços que prestou na colônia.

As posições de Sarmento Rodrigues sobre a importância do esporte podem ser compreendidas pelos três eixos que claramente se articulavam - contribuições para os indivíduos, para a sociedade e para a nação: "Manifesto minha crença no desporto, reconhecendo-lhe a utilidade social de promover a saúde do corpo, tão ameaçada aqui, e a do espírito, indispensável em qualquer parte" (Rodrigues, 1949, p.23).

O esporte, na sua concepção, articulava o material com o simbólico, não somente interferindo no que tange ao corpo propriamente dito, como também forjando valores importantes para os indivíduos e para o desenvolvimento de uma identificação com Portugal, o sentimento de pertença à nação. Por isso, inclusive, fez questão de inserir na programação das comemorações do centenário da descoberta da Costa da Guiné, realizadas em 1945, competições esportivas "de civilizados e indígenas", isto é, de modalidades europeias, mas também de certas práticas das tribos nativas, especialmente algumas lutas. 
As intervenções que Sarmento Rodrigues promoveu no âmbito do esporte estavam articuladas com suas propostas para a Guiné, iniciativas que durante anos repercutiram não só na colônia como também no Império como um todo, antecipando algo que se tornaria mais comum nas décadas seguintes. ${ }^{26}$

Sarmento Rodrigues inaugurou e fez questão de registrar e divulgar um apoio ao esporte que não era ocasional, mas sim integrante de uma política de governo, marcada por preocupações com o desenvolvimento da província e com as peculiaridades e necessidades locais, demonstrando grande respeito pela população, inclusive pelos indígenas, posturas que iriam se manifestar claramente quando ocupasse outros postos no regime.

Não surpreende que alguns dos que com ele participaram daquelas ações no âmbito do esporte na Guiné adotassem propostas semelhantes em outras colônias, em outros momentos da carreira, como é o caso de Peixoto Corrêa, que foi governador de Cabo Verde (1957-1958), governador da Guiné (19581962) e ministro do Ultramar (1962-1965). Essas iniciativas merecem ser mais bem investigadas para que tenhamos ainda maior clareza do papel que a prática esportiva ocupou no pensamento colonial de Portugal, bem como das especificidades do colonialismo português.

\section{REFERÊNCIAS}

CASTELO, Claudia. O modo português de estar no mundo. O luso-tropicalismo e a ideologia colonial portuguesa, 1933-1961. Porto: Afrontamento, 1998.

CRISTÓVÃO, Fernando Alves; AMORIM, Maria Adelina; MARQUES, Maria Lúcia Garcia; MOITA, Susana Brites. Dicionário temático da lusofonia. Lisboa: Texto Editores, 2005.

DRUMOND, Maurício. Estado novo e esporte: a política e o esporte em Getúlio Vargas e Oliveira Salazar (1930-1945). Rio de Janeiro: 7Letras, 2014.

FERNANDES, José Manuel. Arquitetura e urbanismo no espaço ultramarino português. In: BETHENCOURT, Francisco; CHAUDHURI, Kurti (Org.) História da expansão portuguesa: volume V - Último império e recentramento (1930-1998). Lisboa: Círculo de Leitores, 1999. p.334-383.

FERRÃO, Nuno de Sotto-Mayor Quaresma Mendes. Aspectos da vida e obra do Almirante Sarmento Rodrigues (1899-1979). Freixo da Espada à Cinta: Câmara Municipal, 1999.

HENRIQUES, Isabel Castro. Sociedade colonial em África. Ideologias, hierarquias, quotidianos. In: BETHENCOURT; CHAUDHURI (Org.), 1999, cit., p.216-274. 
LÉONARD, Yves. O império colonial salazarista. In: BETHENCOURT; CHAUDHURI (Org.), 1999, cit., p.10-30.

. Salazarisme et Lusotropicalisme, histoire d'une appropriation. Lusotopie, Paris, p.211-226, 1997.

MELO, Victor Andrade. Prática esportiva, cultura e política - diálogos possíveis entre os Estudos do Esporte, os Estudos Africanos e os Estudos Pós-Coloniais. Movimento, Porto Alegre, v.17, n.2, p.155-173, maio 2011a.

(Des)mobilização para a luta: o esporte como estratégia nos conflitos da Guiné portuguesa (décadas de 50 e 60 do séc. XX). Métis: história \& cultura, Caxias do Sul, RS, v.10, n.19, p.215-235, jan.-jun. 2011b.

Jogos de identidade: o esporte em Cabo Verde. Rio de Janeiro: Apicuri, 2011c. . Pequenas-grandes representações do Império Português: a série postal "Modalidades Desportivas" (1962). Estudos Históricos, Rio de Janeiro, v.25, n.50, p.426446, 2012.

MELO, Victor Andrade de; BITTENCOURT, Marcelo; NASCIMENTO, Augusto (Org.) Mais do que um jogo: o esporte no continente africano. Rio de Janeiro: Apicuri, 2010.

MURTEIRA, Mário. Formação e colapso de uma economia colonial. In: BETHENCOURT; CHAUDHURI (Org.), 1999, cit., p.108-130.

NASCIMENTO, Augusto; BITTENCOURT, Marcelo; DOMINGOS, Nuno; MELO Victor Andrade de (Org.) Esporte e lazer na África: novos olhares. Rio de Janeiro: 7Letras, 2013.

NEVES, José. Ler desportivamente Lenine - para a história do comunismo e do desporto em Portugal. Esporte e Sociedade, Niterói, RJ, ano 4, n.11, 2009.

PIMENTA, Fernando Tavares. Portugal e o século XX: Estado-Império e descolonização (1890-1975). Lisboa: Afrontamento, 2010.

PINTO, João Alberto da Costa. Gilberto Freyre e a intelligentsia salazarista em defesa do Império Colonial Português (1951-1974). História, Franca, SP, v.28, n.1, p.445482, 2009.

RODRIGUES, Sarmento. No governo da Guiné. Lisboa: Agência Geral das Colônia/ Divisão de Publicações e Bibliotecas, 1949.

SILVA, António E. Duarte. Guiné-Bissau: a causa do nacionalismo. Cadernos de Estudos Africanos, Lisboa, n.9-10, p.141-167, 2006.

Sarmento Rodrigues, a Guiné e o luso-tropicalismo. Cultura - Revista de História e Teoria das Ideias, Lisboa, v.25, p.31-55, 2008.

\section{NOTAS}

${ }^{1}$ Foi um dos periódicos que teve mais longa trajetória e influência na província (manteve-se ativo até 1968), ainda que, em muitas ocasiões, impresso de maneira bem precária. 
${ }^{2}$ Para mais informações sobre o papel ocupado pelos cabo-verdianos na Guiné, ver Henriques (1999).

${ }^{3}$ Para mais informações sobre o contexto que fortaleceu a necessidade de mudança de rumos na intervenção portuguesa no ultramar, ver Pimenta (2010).

${ }^{4}$ Oficial da Marinha Portuguesa, na época da nomeação era capitão-tenente, depois promovido a capitão de fragata.

${ }^{5}$ No seu discurso de posse no cargo de governador da Guiné, proferido no Ministério das Colônias, em 15 de março de 1945, fez questão de observar que não tinha ligações políticas, sendo antes "um homem que é apenas militar, marinheiro e devotado dos assuntos coloniais" (RODRIGUES, 1949, p.3). Assim intitulou sua fala: "Para o governo da Guiné como para o comando de um navio".

${ }^{6}$ No seu discurso de posse já anunciara essa intenção. Para ele, a "simpatia pelas populações nativas" era um "elemento de valorização do território" (RODRIGUES, 1949, p.5).

${ }^{7}$ Para mais informações, ver Silva (2006).

8 "Confiança no futuro da Guiné", discurso proferido na sessão do Conselho de Estado, Bissau, 25 de abril de 1945.

${ }^{9}$ Para uma análise da administração de Sarmento Rodrigues, ver Silva (2006).

${ }^{10}$ Para um debate sobre o tema, ver Castelo (1998), Léonard (1999) e Pinto (2009).

${ }^{11}$ A UDIB, fundada por funcionários da Alfândega, dos Correios, do Banco Ultramarino e do comércio em geral, com o apoio do então governador Leite de Magalhães, tinha como sócios a elite de Bissau.

${ }^{12}$ O Sporting também agrupava a elite local, mas aceitava alguns membros do estrato intermediário. O outro clube, que surgira em 1944, o Sport Lisboa e Bissau, não enviou representante. Era menos elitista, integrado por muitos cabo-verdianos.

${ }^{13}$ Boletim Cultural da Guiné Portuguesa, Bissau, v.4, n.14, p.384, 1949.

${ }^{14}$ O Arauto, Bolama, ano 2, n.19, p.2, nov. 1944.

${ }^{15}$ Para mais informações sobre o esporte em Cabo Verde, ver Melo (2011c).

${ }^{16}$ O Arauto, Bolama, ano 2, n.23, mar. 1945.

${ }^{17}$ Boletim Cultural da Guiné Portuguesa, Bissau, v.1, n.1-4, p.347, 1946.

${ }^{18}$ O Arauto, Bolama, ano 2, n.24, abr.1945.

${ }^{19}$ Boletim Cultural da Guiné Portuguesa, Bissau, v.2, n.7, p.813, 1947.

${ }^{20}$ Boletim Cultural da Guiné Portuguesa, Bissau, v.3, n.10, p.493, 1948.

${ }^{21}$ Boletim Cultural da Guiné Portuguesa, Bissau, v.3, n.10, p.495, 1948.

${ }^{22}$ Boletim Cultural da Guiné Portuguesa, Bissau, v.3, n.10, p.498, 1948.

${ }^{23}$ Boletim Cultural da Guiné Portuguesa, Bissau, v.3, n.11, p.811, 1948. 
Victor Andrade de Melo

${ }^{24}$ Futuramente seu nome também seria dado ao estádio de São Tomé e Príncipe e a um estádio em Limpopo, Moçambique.

${ }^{25}$ Boletim Cultural da Guiné Portuguesa, Bissau, v.4, n.15, 1949.

${ }^{26}$ Sobre o tema, ver, por exemplo, Melo (2012).

Artigo recebido em 18 de agosto de 2014. Aprovado em 22 de outubro de 2014. 